\title{
MAGNETIC-PULSE CAR BODY PANELS FLATTENING. THEORETICAL ASPECTS AND PRACTICAL RESULTS
}

\begin{abstract}
The aim of the article is to provide theoretical and experimental studying of the «induction system with an attractive screen" practical effectiveness with the excited magnetic pulse attractive forces numerical estimation. Originality. For the first time, the theoretical analysis of the electrodynamics process for the "inductor system with attractive screen" at the low frequent assumption were conducted. Methodology of the analysis applied is based on the classic electrodynamics circuits theory. All of the resulted carried out, were obtained as the Maxwell's differential equation solutions and its behavior was analyzed analytically. Results. The electrodynamics process was analyzed and the principle efficiency of the "induction system with an attractive screen" as an effective tool for magnetic pulse forming of the thin sheet metals was substantiated. The axis distributions of the attractive forces based on the relations been obtained were illuminated graphically. The results of experimental testing of the system in the engineering operation of the external non-contact dents removing on the car body panels samples were presented. Practical value. According to the results of the calculation analyses the fundamental workability of the «inductor system with attractive shield» as an effective magnetic pulse sheet metal part attraction tool was proved. It was shown that the not deep metal surface damages could be worked up by magnetic pulses technologies with a high performance in a short time. References 12, figures 4.

Keywords: magnetic-pulse forming, inductor system, field tension, inducted current density, electromagnetic processes.
\end{abstract}

Проведен анализ электродинамических процессов и обоснована принципиальная работоспособность «индукторной системы с притягивающим экраном", как эффективного инструмента магнитно-импульсной рихтовки тонкостенных листовых металлов. Представлены результаты экспериментальной апробации системы в производственной операции по внешнему бесконтактному удалению вмятин в образцах кузовных панелей автомобилей. Библ. 12 , рис. 4. Ключевые слова: магнитно-импульсная рихтовка, индукторная система, напряженность поля, плотность индуцированных токов, электромагнитные процессы.

Introduction and publications analysis. The applying of magnetic fields for metals engineering is widely used [1]. Now, the contemporary technologies allow to make production available and technically simple of the complexes for electromagnetic-pulse metals forming (EMF). Currently EMF technology got widespread throughout the world [2]. Therefore, firms like «Boeing», «Electroimpact» and «Flextronic» use this technology for repair namely to remove dents on the fuselage of the aircraft $[3,4]$. We should note so company like «Betag Innovation» (last «Beule Technik $A G »)$ that has the practice-approved experience at the area of the development of various systems for the car body panels dents removing [5].

In the laboratory of the electromagnetic technologies at the Kharkiv National Automobile and Highway University (KhNAHU) the developments in the area of the magnetic pulse metal forming (MPMF) takes a place.

The complex (prototype) for the external magneticpulse car body panels flattening, that is consist of the power source and the magnetic-pulse tool series for dents removing was developed and made [6].

The power source that in special literature called like magnetic pulse plant (MPP) is a universal devise in its essence, withal, the tools - the magnetic field sources, that are called inductor systems, must satisfy the carrying out operations correctly $[1,2]$.

In particular, the main purpose of the magneticpulse metal processing consists in the external noncontact car body metal flattening. The detailed enough review of these tools, repairing technologies, its appearance and historical development aspects in the treaties [7] are presented.

According to the work principle, all tools can be divided in two big groups. So, the performance of the first group is based on the sheet metal attraction, that is caused by curtain magnetic properties under such condition as low frequency of the action field $[8,9]$. The effectiveness of the second group tools, that have an author's name «inductor system with an attractive shield (ISAS)», is determined by conductors forced attraction, that have same directional inducted Fouke's currents and is described by Ampere's low. This system consists constructively of the field source- inductor that is placed between two sheet metal conductors. One of them - is the auxiliary attractive shield, another one is the sheet metal simple, the current area of which is subjected to the attractive magnetic pulse influence [8-10].

One of the ISAS constructions is proposed by authors of the patent [11]. It supposes circle inductor, conductive auxiliary shield and sheet metal sample layer-tolayer placing. Respectively, such construction of the inductor system can be an effective enough tool for the contemporary technologies of the automobile body panel dents removing [12].

Purpose of the article is theoretical and experimental studying of the ISAS practical effectiveness with the excited magnetic pulse attractive forces numerical estimation. The ISAS practical testing as a tool for new method of external car bodies flattening with protective paintwork saving. The description of the external non-contact magnetic pulse flattening technological route.

Theory, calculated ratio. The accepted calculated model of the cylindrical inductor system (tool) design for the magnetic-pulse flattening with equal thin-walled nonmagnetic sheet metals and the flat circular one-coil solenoid that placed above the attractive shield surface is presented in fig. 1.

According to the articles [2, 8-10] the mathematical assumptions were accepted.

For the calculated model fig. 1 Maxwell's equations were composed, solution of which gives us the inducted (C) Yu.V. Batygin, E.A. Chaplygin, O.S. Sabokar 
currents time form. (Detail calculation sequence can be reviewed in [1, 2, 7-10]). At the low frequency work mode for the action fields, currents can be presented in the next form.

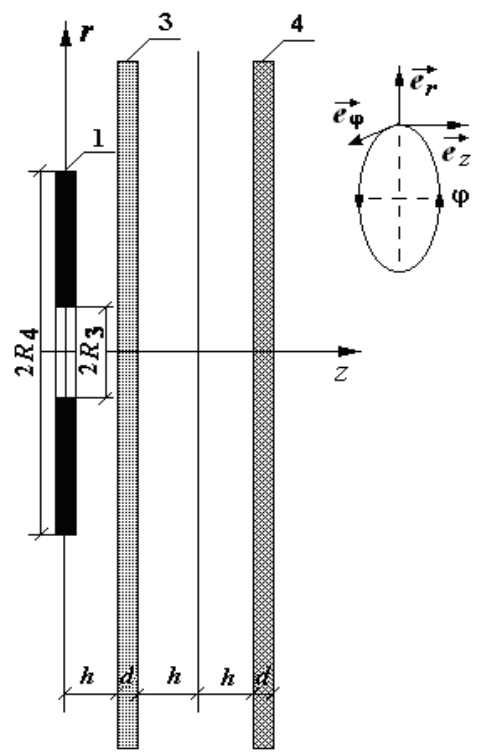

Fig. 1. The calculated model in a cylindrical coordinate system: 1 - multicoil inductor; 2 - shield; 3 -sample; $d$-thickness; $R_{3}, R_{4}$ - inner and outer radii; $h$ - the distance from the inductor to the shield, $2 h$ - the distance between the shield and the metal sample; $\vec{e}_{r}, \vec{e}_{\varphi}, \vec{e}_{z}-$ directing vectors

The excited signal in the auxiliary shield:

$$
J_{\phi}^{(s)}(\psi, r)=-J_{m} \cdot \int_{0}^{\infty} f(x) \cdot \frac{e^{-x \frac{h}{d}}\left(1-e^{-x}\right)}{x} J_{1}\left(x \cdot \frac{r}{d}\right) d x,
$$

where $J_{m}=\left(\frac{I_{m}}{R_{4}-R_{3}}\right) \cdot \frac{\omega \tau}{2} \cdot \frac{d g(\psi)}{d \psi}-$ the «conditional» induced signal amplitude, $I_{m}$ and $g(\psi)=e^{-\delta_{0} \psi} \cdot \sin (\psi)-$ the amplitude and the phase relation of the excited current in the solenoid; $\psi=\omega \cdot t$ - phase, $t$ - time,

$$
f(x)=\frac{1}{x^{2}} \cdot \int_{x \frac{R_{3}}{d}}^{x \frac{R_{4}}{d}} y \cdot J_{1}(y) d y .
$$

The linear current density that is excited in the sheet metal sample:

$$
J_{\phi}^{(p)}(\psi, r)=-J_{m} \cdot \int_{0}^{\infty} f(x) \cdot e^{-x \cdot\left(\frac{3 h}{d}+1\right)} \cdot \frac{\left(1-e^{-x}\right)}{x} J_{1}\left(x \frac{r}{d}\right) d x .
$$

At the consider low frequency mode, as there have been shown before, the attractive forces integral efficiency tends to zero value $[2,10]$.

Under conditions of the hard auxiliary shield fixation, the sample will be subjected only to the attractive forces influence. The attractive forces (Ampere's forces) dependence that presents in the terms of the inductor current phase takes the next form [10].

$$
F_{\text {attr }}(\psi, r)=\mu_{0} \cdot J_{\phi}^{(s)}(\psi, r) \cdot J_{\phi}^{(p)}(\psi, r) \cdot \frac{r}{(2 h)} .
$$

The numerical estimations were made according to the next initial data that is typical for the magnetic pulse metal processing $[1,2]: I_{m}=120 \mathrm{kA}, \omega=2 \pi \cdot 1500 \mathrm{~Hz}$, $R_{3}=0.005 \mathrm{~m}, R_{4}=0.05 \mathrm{~m}, d=0.001 \mathrm{~m}, h=0.005 \mathrm{~m}$.

Calculation results in the fig. 2 are presented.

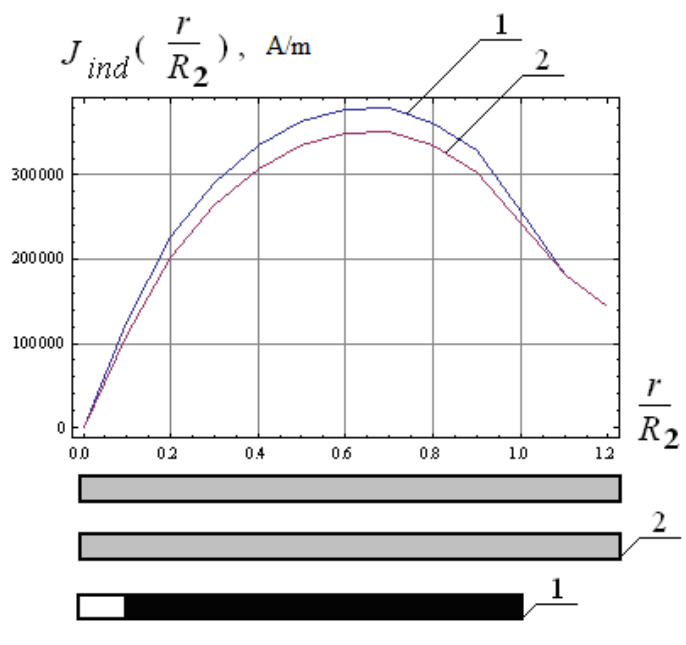

$a$

$F_{\text {attr }}\left(\frac{r}{R_{2}}\right), \mathrm{kgf} / \mathrm{cm} 2$
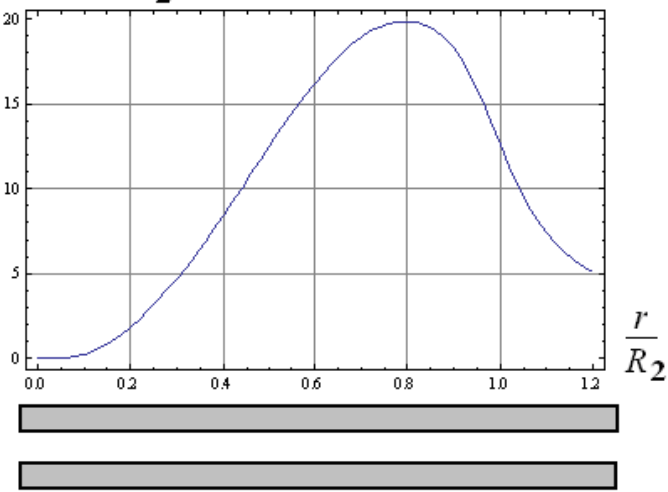

$b$

Fig. 2. Spatial excited currents and attractive forces distribution: a) the currents induced in the auxiliary shield metal -1 and sheet metal sample -2 ;

$b$ ) is the radial attractive forces distribution

On the calculated dependences in the fig. 2 it is obtained that achieved attractive forces can reach up to 20 Atm. in the researched ISAS system.

The averaged surface forced impact is equal to 10 Atm. It is necessary to attend, that insignificant increase of the current, e.g., up to $150 \mathrm{kA}$, (that is real enough practically) gives us more than 2 times attractive forces value increase. As the practice of magnetic-pulse metals processing, this forced impact value is enough for effective deformation of the thin walled conductors. Ultimately, the main result of the analysis of electrodynamic processes is the conclusion about the practical effectiveness of the proposed ISAS construction.

Experimental testing and the main results. The ISAS principal construction that is used in experiments and coincides with its calculated model.

Actually, based on the forced impact results, the proposed «inductor system with attractive shield» is 
analogical to the well-known electromagnet, fig $3, b$. However, unlike the last, there can be realized the attraction not only for ferromagnetic, but also for metal of any physical nature.

In the fig. 3 the magnetic pulse flattening complex and the experimental ISAS prototype are presented. The winding of the exciting coil is connected to the power source - magnetic pulse plant МИУС-2, that was designed and developed in the Laboratory of electromagnetic technology KhNAHU, fig 3,a [6]. Its distinguishing feature consists of the serial pulse work mode. It means continuously predetermined number of charge current pulses repetition, that eventually are transformed into the power attraction pulses of the metal dents to the working shield surface.

As experimental samples there were taken galvanized steel sheet metal samples and car body metal samples so Automobile mark like «Subaru» and «Citroen». The samples thickness was $\sim 0.0008 \ldots 0.001 \mathrm{~m}$. The damages, that were made in each sample were $0.0018 \ldots 0.002 \mathrm{~m}$ and external diameter was $0.05 \mathrm{~m}$.
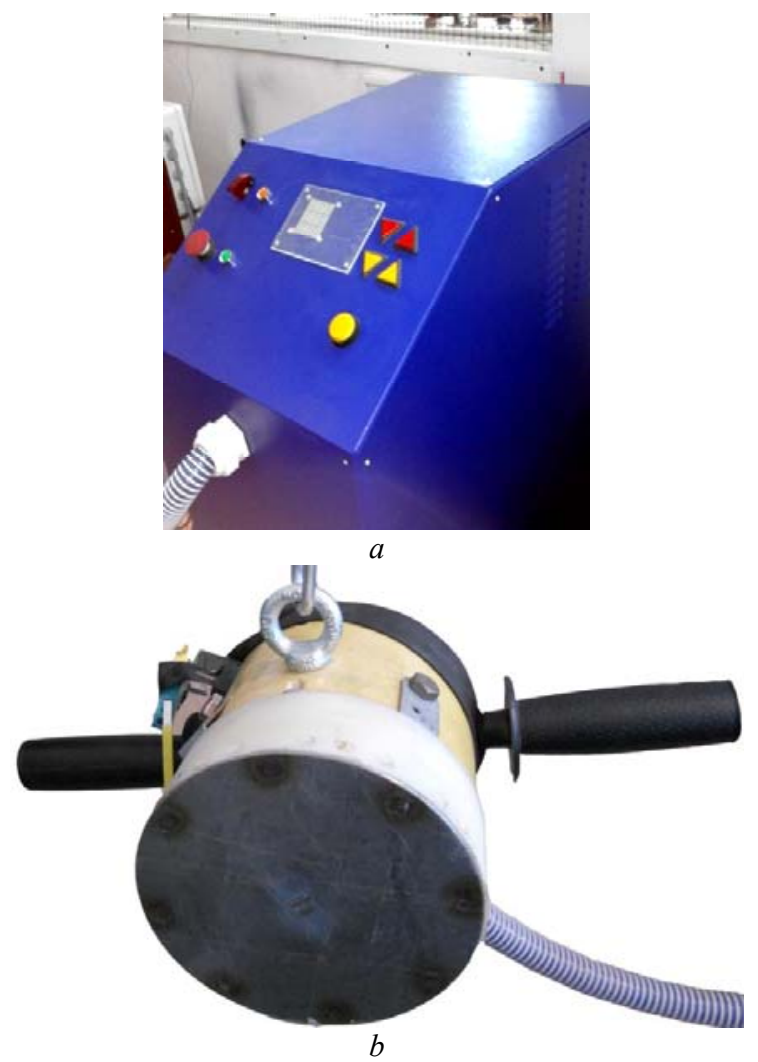

Fig. 3. The external magnetic pulse flattening complex ( 1 - magnetic pulse flattening tool - ISAS); 2 - the cable connection; 3 - magnetic pulse plant MИУС2): $a$ - common complex view; $b$ - ISAS

The technological operations was carried out under the following terms:

- stored energy and the voltage of the capacitive storage $\sim 2.4 \mathrm{~kJ}$ and $1500 \mathrm{~V}$, respectively;

- working frequency and the current pulse amplitude $\sim 1500 \mathrm{~Hz}$ and $\sim 12 \mathrm{kA}$, respectively;

- current pulses frequency $\sim 5 \mathrm{~Hz}$;

- power attraction pulses number, that provides alignment of the sheet sample with a dent $\sim 18 \ldots 20$.
In the fig. 4 there are presented the experimental samples that illustrate examples of effective external noncontact magnetic pulse dents removing in samples of cars body panels of the Japanese and European production. It is necessary to note about the safety of the protective cover lay.
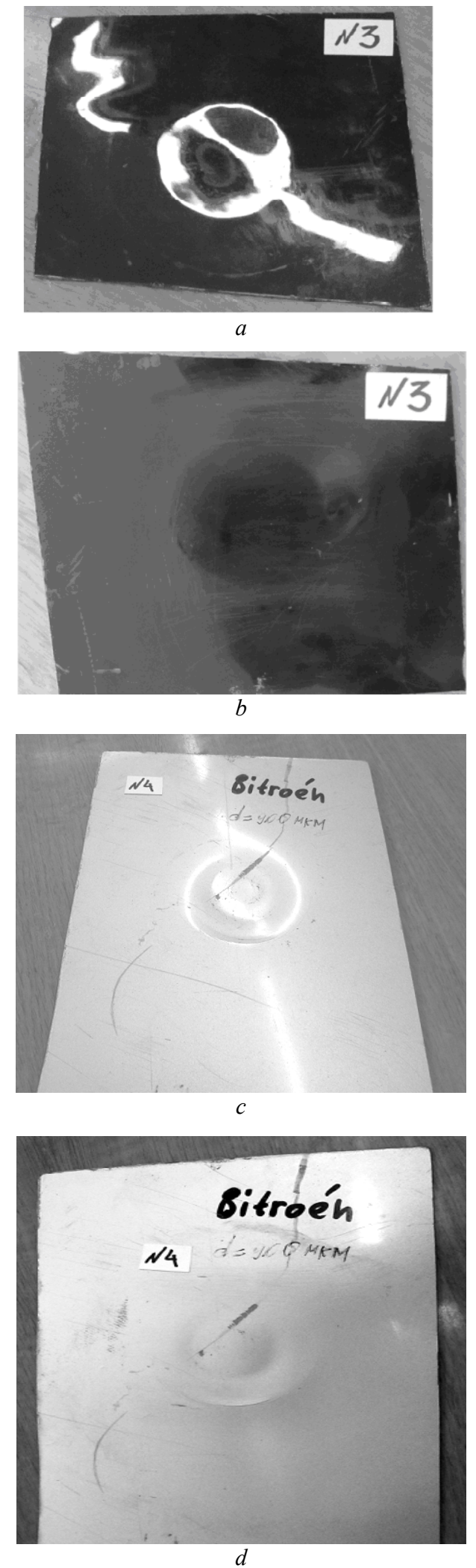

Fig. 4. The experimental samples variety of automotive steels: «Subaru» ( $a$ - before the power impact, $b$ - after attraction); «Citroen» ( $c$ - before the power impact, $d$-after attraction) 


\section{Conclusions.}

1. At the low frequent assumption, the theoretical analysis of the electrodynamical process for the «inductor system with attractive shield» with the external one coil circle inductor exciting were conducted.

2. The fundamental workability of the «inductor system with attractive shield» as an effective magnetic pulse sheet metal part attraction tool was proved.

3. The successful experimental testing of the «inductor system with attractive shield» and external exciting for the actual external non-contact dent removing operation in the European and Japan car body samples was conducted.

4. The external magnetic pulse flattening technical rout was disclosed and described.

5. The experiment results showed us the efficiency of the proposed magnetic pulse flattening tool in the practical realization for the principally new flattening method with a paintwork covering saving.

\section{REFERENCES}

1. Psyk V., Risch D., Kinsey B.L., Tekkayaa A.E., Kleiner M. Electromagnetic forming - A review. Journal of Materials Processing Technology, 2011, vol.211, no.5, pp.787-829. doi: 10.1016/j.jmatprotec.2010.12.012.

2. Batygin Yu.V., Lavinskiy V.I., Khimenko L.T. Impul'snyye magnitnyye polya dlya progressivnykh tekhnologiy. Tom 1. Izdaniye vtoroye, pererabotannoye i dopolnennoye. [Pulsed magnetic fields for advanced technologies. Vol.1. 2nd edition, revised and enlarged.] Kharkov, MOST-Tornado Publ., 2003. 284 p. (Rus).

3. Electromagnetic Dent Removal. Available at: http://www.electroimpact.com/EMAGDR/overview.asp cessed 25 May 2014).

4. Need an electromagnetic dent remover on hand. Fluxtronic offers the best: the Portable Flux 3 dent remover. Available at: http://www.fluxtronic.com/product.php (accessed 07 August 2014).

5. Welcome to BETAG Innovation. Available at http://www.betaginnovation.com (accessed 16 June 2014).
6. Laboratoriia elektromagnitnykh tekhnologii (Laboratory of Electromagnetic Technology) Available at: http://electromagnetic.comoj.com (accessed 10 July 2014).

7. Yuriy V. Batygin, Sergey F. Golovashchenko, Andrey V. Gnatov. Pulsed electromagnetic attraction of sheet metals fundamentals and perspective applications. Journal of Materials Processing Technology, 2013, vol.213, no.3, pp. 444-452. doi: 10.1016/j.jmatprotec.2012.10.003.

8. Batygin Yu.V., Gnatov A.V. Magnetic-pulse attraction and repulsion of thin-walled sheet ferromagnetics. Electrical Technology Russia, 2012, no.8, pp. 58-65. (Rus).

9. Batygin Yuri V., Sergey F. Golovashchenko, Andrey V. Gnatov. Pulsed electromagnetic attraction of nonmagnetic sheet metals. Journal of Materials Processing Technology, 2014, vol.214, iss.2, pp. 390-401. doi: 10.1016/j.jmatprotec.2013.09.018.

10. Batygin Yu.V., Golovashhenko S.F., Chaplygin E.A. Magnetic-pulse attraction of nonmagnetic metals. Electrical Technology Russia, 2014, no.2, pp. 40-52. (Rus).

11. Batygin Yu.V., Gnatov A.V., Chaplygin E.O., Trunova I.S., Gopko A.V., Sabokar O.S. Sposib magnitno-impul'snogo prityagannya metalevih zagotivok odnovitkovim krugovim induktorom, roztashovanim nad dopomizhnim ekranom [Method of the magnetic-pulse attraction metal workpeaces single-turn circular inductor located on the auxiliary screen]. Patent UA, no.77579, 2013. (Ukr).

12. Batygin Yu.V. Experimental test of the tool for the external EMF removing dents on a car body. International Journal of Energy and Power Engineering, 2014, vol.3, no.4, pp. 204-208. doi: 10.11648/j.ijepe.20140304.14.

Received 25.03.2016

Yu.V. Batygin ${ }^{1}$, Doctor of Technical Science, Professor, E.A. Chaplygin ${ }^{1}$, Candidate of Technical Science, Associate Professor,

O.S. Sabokar ${ }^{1}$

${ }^{1}$ Kharkov National Automobile and Highway University, 25, Petrovskogo Str., Kharkov, 61002, Ukraine. phone+38057 7073727, e-mail: batygin48@mail.ru, chaplygin.e.a@gmail.com, o.s.sabokar@gmail.com

How to cite this article:

Batygin Yu.V., Chaplygin E.A., Sabokar O.S. Magnetic-pulse car body panels flattening. Theoretical aspects and practical results. Electrical engineering \& electromechanics, 2016, no.4, pp. 54-57. doi: 10.20998/2074-272X.2016.4.07. 